\title{
MORTALITY RESPONSE OF CODLING MOTH TO METHYL BROMIDE FUMIGATION AND COOLSTORAGE
}

\author{
B.C. WADDELL and R.J. PETRY \\ HortResearch, Mount Albert Research Centre, Private Bag 92169, \\ Auckland, New Zealand
}

\begin{abstract}
Complete mortality of one-day old codling moth eggs infesting Red Delicious apples was achieved by fumigation with methyl bromide at $24 \mathrm{~g} / \mathrm{m}^{3}$ for $2 \mathrm{~h}$ at $12.0 \pm 0.5^{\circ} \mathrm{C}$, followed by $18 \mathrm{~d}$ coolstorage at mean fruit pulp temperatures in the range $0.52-1.77^{\circ} \mathrm{C}$. Non-fumigated coolstored eggs required a period of $33 \mathrm{~d}$ exposure at the same temperatures to achieve complete kill. Fumigation followed by coolstorage of small numbers of fifth instar larvae resulted in complete mortality of this life stage after $26 \mathrm{~d}$, the only duration tested. The postharvest disinfestation treatment currently used to export apples to Japan involves fumigation with methyl bromide (as above) followed by a mandatory $25 \mathrm{~d}$ coolstorage period at temperatures of $0.5^{\circ} \mathrm{C}$ and below. Therefore the approved treatment specification used for export apples is very robust in both its coolstorage duration and temperature range.
\end{abstract}

Keywords: Cydia pomonella, disinfestation, methyl bromide, apples

\section{INTRODUCTION}

New Zealand fresh fruit exports to the Japanese market, where insect quarantine issues exist, rely on the application of a postharvest disinfestation treatment. Codling moth, Cydia pomonella (L.), is an important pest species which is not found in Japan. Cherry and nectarine fruits must undergo fumigation with methyl bromide at dose rates of $64 \mathrm{~g} / \mathrm{m}^{3}$ for $2 \mathrm{~h}$ at $12.0 \pm 0.5^{\circ} \mathrm{C}$ to control codling moth eggs (Maindonald et al. 1992; Waddell et al. 1989). However, this rate is beyond the tolerance limits of a number of apple cultivars (Lay-Yee, 1993). Coolstorage has been demonstrated as an effective method of killing codling moth eggs and larvae. However, the times required to kill the more tolerant diapausing larval life stages (12 or more weeks) are too long to be commercially applicable (Moffitt and Albano, 1972; Toba and Moffitt, 1991). A combination of coolstorage followed by methyl bromide fumigation is the approach that has been adopted for treatment of apples. This allows a reduction in both the length of time required in coolstorage and the methyl bromide dose. This approach has been adopted in the United States for controlling codling moth (Warner 1995) and in Japan for controlling a similar lepidopteran apple pest, the peach fruit moth, Carposina niponensis (Kawakami et al. 1994).

The New Zealand treatment involves methyl bromide fumigation followed by coolstorage (the reverse order of the United States and Japanese treatments) as a twocomponent treatment to disinfest apples of codling moth. The final treatment specification approved by the Japanese Ministry of Agriculture, Forestry and Fisheries (MAFF) was fumigation at $24 \mathrm{~g} / \mathrm{m}^{3}$ for $2 \mathrm{~h}$ at $\geq 12^{\circ} \mathrm{C}$, followed by $25 \mathrm{~d}$ coolstorage at $0.5^{\circ} \mathrm{C}$ or below (Waddell et al. 1992). In commercial practice expensive, specialised coolstorage facilities are required to maintain apple flesh temperatures at $0.5^{\circ} \mathrm{C}$ or below for the mandatory period without either short periods above $0.5^{\circ} \mathrm{C}$ and/or exposing the fruit to temperatures below $0^{\circ} \mathrm{C}$ which might result in fruit damage. Therefore, as part of the development of the apple disinfestation treatment, this preliminary trial was conducted to determine the effect of elevated coolstorage 
temperatures on the mortality response of codling moth eggs, the life stage most tolerant of fumigation (Dentener et al. 1988). In addition a small number of diapausing fifth instars, the life stage most tolerant to coolstorage (Dentener et al. 1988), were evaluated at one storage time to verify the treatment efficacy at different temperatures.

\section{METHODS}

Codling moths were obtained from a colony maintained on artificial diet (Singh et al. 1985) using a L:D 16:8 photoperiod, a temperature of $25.0^{ \pm} 1.0^{\circ} \mathrm{C}$, and a relative humidity of approximately $60 \%$. Fruit were exposed to adult moths for $24 \mathrm{~h}$ to obtain young eggs for treatment the following day. Fifth instars programmed for diapause when reared on laboratory diet for $12-13$ days at $25^{\circ} \mathrm{C}, \mathrm{L}: \mathrm{D} 12: 12$ were inoculated into each fruit the day before treatment. All fruit was equilibrated to $12^{\circ} \mathrm{C}$ prior to treatment, which involved either fumigation followed by coolstorage for eggs and larvae or coolstorage only for eggs. Fumigations were conducted at atmospheric pressure in an $11.15 \mathrm{~m}^{3}$ chamber using $1518 \mathrm{~kg}$ of Red Delicious apples packed in wooden bins. Fruit comprised both infested fruit and non-infested filler which represented a $40 \%$ (volume to volume) chamber loading. All fumigation conditions were identical to those subsequently approved by the Japanese MAFF (Waddell 1992).

During fumigation the methyl bromide concentration was measured with a gas chromatograph (Varian 3700) at 5, 10, 30, 60, 90 and 120 minutes. This allowed verification of the initial concentration and determination of the total amount of gas absorbed by the fruit.

After fumigation, the infested fruit was kept at $12^{\circ} \mathrm{C}$ until the following day when one-tenth of the fruit was placed at $25^{\circ} \mathrm{C}$ and egg hatch was assessed $8 \mathrm{~d}$ later. The remaining fruit was split into three trial lots, packed into cardboard apple cartons and coolstored at one of three target fruit pulp temperature ranges; 0.5-1.0, 1.0-1.5, 1.5$2.0^{\circ} \mathrm{C}$. Six samples of fumigated fruit were removed after various exposure times $(3,4.5$, $6,12,18,26 \mathrm{~d})$ from each coolstore to obtain a range of mortalities for statistical analyses. Non-fumigated fruit was kept at $12^{\circ} \mathrm{C}$ for $1.5 \mathrm{~d}$ and then approximately onequarter was placed at $25^{\circ} \mathrm{C}$ and the remaining three-quarters was split into three lots and coolstored at the different temperature ranges. Seven samples of non-fumigated infested fruit were removed after various coolstorage exposure times (as above plus $33 \mathrm{~d}$ ).

Fifth instars were fumigated and then coolstored for one duration of $26 \mathrm{~d}$ at each of the coolstore temperature ranges used for eggs. This coolstorage duration allowed for a cool down period of approximately $24 \mathrm{~h}$ in addition to the $25 \mathrm{~d}$ required at temperatures of $0.5^{\circ} \mathrm{C}$ and below. Replicate trials, two in total, were conducted on consecutive days. Larvae that had been fumigated only and non-fumigated noncoolstored control larvae were kept at $25^{\circ} \mathrm{C}, \mathrm{L}: \mathrm{D} 12: 12$, and were assessed on the third day after fumigation treatment.

Mortality assessments were made 3 and $8 \mathrm{~d}$ after removal from coolstorage for larvae and eggs respectively. Coolstore air temperatures and fruit centre temperatures were monitored with 14-channel Grant Squirrel data loggers (Model 1206) at hourly intervals. Japanese MAFF requirements for temperature monitoring of the coolstores were not known when these trials were conducted, and so extensive monitoring was conducted particularly of the infested fruit. Air temperature was measured $30 \mathrm{~cm}$ below the coolstore ceiling while some fruit pulp (or core) temperatures were measured at various locations in the fruit stack (top, middle and bottom layer). Fruit stacks were three cartons wide by four cartons deep by five cartons high, except the $0.5-1.0^{\circ} \mathrm{C}$ target coolstore which was smaller allowing only a three carton deep stack of apples. All infested fruit was placed in the second layer from the top of the fruit stack. Fruit pulp measurements were made in cartons containing infested and noninfested fruit. Six probes were available for recording fruit temperatures in the 0.5-1.0 and $1.0-1.5^{\circ} \mathrm{C}$ target stores and thirteen probes in the $1.5-2.0^{\circ} \mathrm{C}$ coolstore. Mean fruit pulp temperature calculations excluded the cool down period from $12^{\circ} \mathrm{C}$ to the target range upper limit (i.e. 1.0, 1.5 and $2.0^{\circ} \mathrm{C}$ ). All fruit temperatures declined below the various upper limits operating in each coolstore in 8-11, 15-19 and 25-28 $\mathrm{h}$ for the $0.5-1.0,1.0-1.5$ and $1.5-2.0^{\circ} \mathrm{C}$ coolstores, respectively. 
Time-mortality data were analysed using the complementary log-log (cloglog) model (Preisler and Robertson, 1989). The assumed form of the response was:

$\log (-\log (1-p))=a+b t$

where $p=$ expected mortality, and $\mathrm{t}=$ time in days. The line was then used to determine the estimated lethal time in days for $99 \%\left(\mathrm{LT}_{99}\right)$ mortality. The $\mathrm{LT}_{99}$ is the estimated lethal time to achieve $c+(1-c) 0.99$ mortality, where $c$ was the mortality of non-fumigated and non-coolstored eggs. Initial analyses were completed for the separate response lines. Egg data were then divided into two groups: fumigated and non-fumigated, and a line fitted to the combined data. The dispersion for each group was compared with that of the separate trials. In both cases there was no difference in the dispersion $(\mathrm{P}=0.01)$. It was therefore reasonable to consider the three egg trials as replicates within a temperature range of 0 to $2^{\circ} \mathrm{C}$.

\section{RESULTS}

Sorption of methyl bromide during the two fumigations was 28.1 and $23.7 \%$ of the initial concentration. These figures indicate that a high level of free gas was present at the end of the fumigation. The mean air and fruit pulp temperatures achieved during the coolstorage period were within the three target ranges (Table 1, Fig. 1). Larger standard deviations associated with the $0.5-1.0^{\circ} \mathrm{C}$ coolstore were a consequence of a technical malfunction in the coolstore resulting in a temporary $(<14 \mathrm{~h})$ drop in temperature. Codling moth mortality did not appear to be affected as a result.

Codling moth mortality in response to fumigation only was $75.1 \%$ for eggs $(n=1029)$ and $95 \%$ for larvae $(n=99)$ compared to non-fumigated egg and larval mortalities of $30.6 \%(n=2964)$ and $2.3 \%(n=172)$, respectively. The $\mathrm{LT}_{99}$ s estimated for eggs which had only been coolstored were 3-4 times longer than those for eggs which had been fumigated prior to coolstorage (Fig. 2). Irrespective of whether the eggs were fumigated prior to coolstorage $(n=19603)$ or those which were only coolstored $(\mathrm{n}=8508)$, no significant difference was evident between egg mortalities when stored at the different temperature ranges. Hence mean fruit temperatures in the range $0.52-1.77^{\circ} \mathrm{C}$ had no effect on the time required to achieve $99 \%$ mortality of codling moth eggs. Combining the results from the three individual coolstores resulted in mean $\mathrm{LT}_{99} \mathrm{~s}$ of $6.4 \mathrm{~d}$ for fumigated and coolstored eggs and $23.7 \mathrm{~d}$ for eggs which had only been coolstored (Table 2 ).

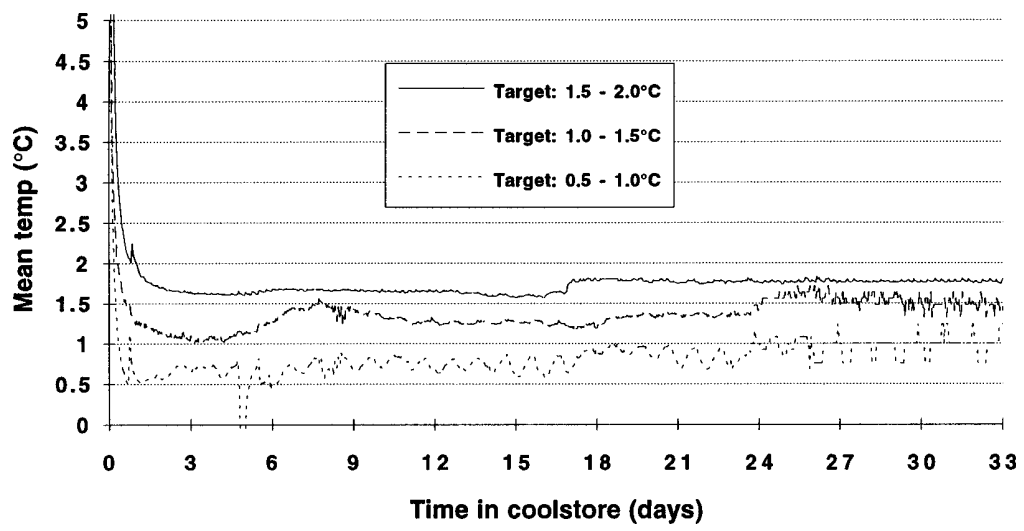

FIGURE 1: Mean fruit centre temperatures calculated from all the individually probed Red Delicious apples monitored in cartons in each of three coolstores operating at different target temperatures. (Values between 5 and $12^{\circ} \mathrm{C}$ excluded from plot.) 
TABLE 1: Individual probe values for air and fruit pulp temperatures monitored in three coolstores containing codling moth infested ' $R$ ed Delicious' apples. Tabulated values exclude the initial fruit cooling period ${ }^{1}$.

\begin{tabular}{|c|c|c|c|}
\hline $\begin{array}{c}\text { Target } \\
\text { Temperature } \\
\text { Range }\left({ }^{\circ} \mathrm{C}\right)\end{array}$ & $\begin{array}{l}\mathrm{A}=\mathrm{Air} \\
\mathrm{F}=\text { Fruit Temp. } \\
\text { (layer number) }^{2}\end{array}$ & Mean & SD \\
\hline $0.5-1.0$ & $\begin{array}{c}\mathrm{A}^{3} \\
\mathrm{~F}(3) \\
\mathrm{F}(2) \\
\mathrm{F}(2) \\
\mathrm{F}(2) \\
\mathrm{F}(2) \\
\mathrm{F}(2)\end{array}$ & $\begin{array}{l}0.52 \\
0.71 \\
0.70 \\
0.73 \\
0.69 \\
0.71 \\
0.77\end{array}$ & $\begin{array}{l}0.85 \\
0.21 \\
0.29 \\
0.26 \\
0.38 \\
0.37 \\
0.39\end{array}$ \\
\hline $1.0-1.5$ & $\begin{array}{c}\text { A } \\
F(3) \\
F(2) \\
F(2) \\
F(2) \\
F(2) \\
F(2)\end{array}$ & $\begin{array}{l}1.12 \\
1.37 \\
1.29 \\
1.34 \\
1.23 \\
1.23 \\
1.18\end{array}$ & $\begin{array}{l}0.76 \\
0.16 \\
0.10 \\
0.11 \\
0.13 \\
0.12 \\
0.13\end{array}$ \\
\hline $1.5-2.0$ & $\begin{array}{c}\text { A } \\
F(1) \\
F(3) \\
F(5) \\
F(2) \\
F(2) \\
F(2) \\
F(2) \\
F(2) \\
F(2) \\
F(2) \\
F(2) \\
F(2) \\
F(2)\end{array}$ & $\begin{array}{l}1.77 \\
1.68 \\
1.65 \\
1.77 \\
1.65 \\
1.70 \\
1.71 \\
1.58 \\
1.57 \\
1.71 \\
1.75 \\
1.77 \\
1.62 \\
1.67\end{array}$ & $\begin{array}{l}0.58 \\
0.07 \\
0.07 \\
0.05 \\
0.07 \\
0.08 \\
0.07 \\
0.10 \\
0.08 \\
0.07 \\
0.08 \\
0.08 \\
0.03 \\
0.05\end{array}$ \\
\hline
\end{tabular}

${ }^{1}$ The time taken to reduce the temperature from the initial $12^{\circ} \mathrm{C}$ to the upper limit of the target range was excluded from the calculations. Periods of 8-11, 15-19 and 25-28 h were excluded from $0.5-1.0,1.0-1.5$ and $1.5-2.0^{\circ} \mathrm{C}$ target ranges, respectively. Cool down periods varied with replicate.

${ }^{2}$ Fruit stacks were five cartons high with layer 1 being the top layer. All codling moth infested fruit was located in the second layer from the top.

${ }^{3}$ One 14-channel data logger was shared between the two coolstores operating at targets of $0.5-1.0$ and $1.0-2.0$, hence only seven probes were available for each coolstore.

Complete mortality of non-fumigated eggs was observed by $33 \mathrm{~d}$ exposure to coolstorage under each of the temperature ranges tested while fumigated eggs were all killed by $18 \mathrm{~d}$ exposure with very high levels of mortality $(99.97 \%)$ after $12 \mathrm{~d}$ exposure. When fifth instars were assessed after fumigation followed by $26 \mathrm{~d}$ coolstorage, the only storage duration evaluated, complete mortality was achieved for all three temperature ranges tested $(n=910)$. These times include a cool-down period of up to $28 \mathrm{~h}$ duration, by which time all of the infested fruit was within the target range. 


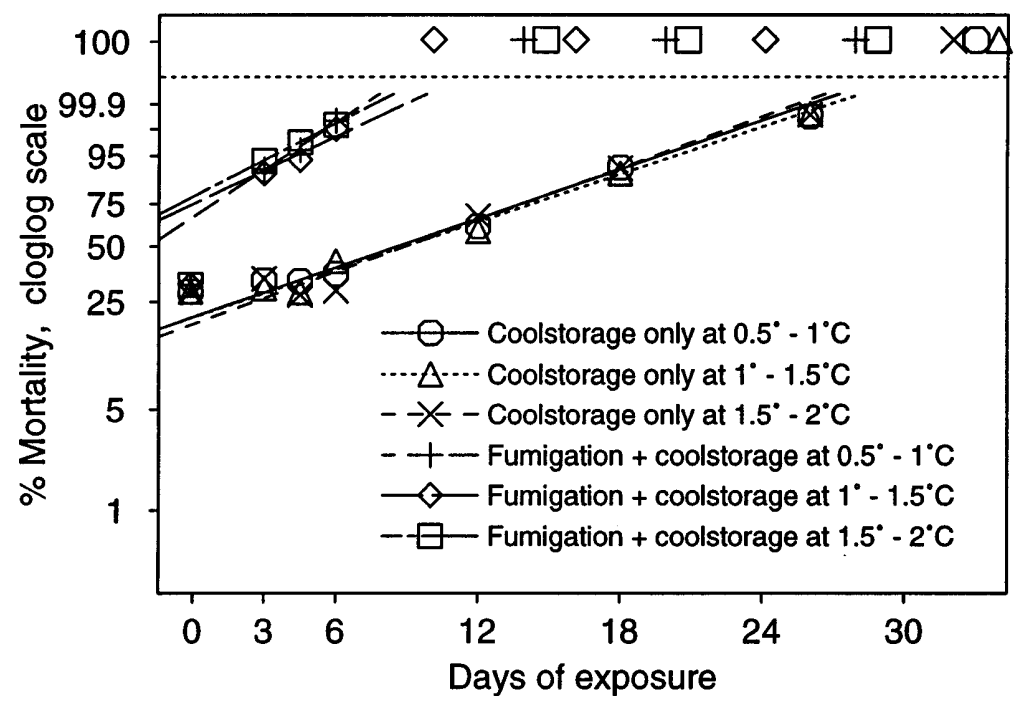

FIGURE 2: Mortality of codling moth eggs infesting 'Red Delicious' apples and placed in coolstorage at three different target fruit pulp temperature ranges. Fruit were either coolstored only or were fumigated with methyl bromide at $24 \mathrm{~g} / \mathrm{m}^{3}$ for $2 \mathrm{~h}$ at $12 \pm 0.5^{\circ} \mathrm{C}$ prior to coolstorage at the different temperatures. Exposure times include times taken to reduce the fruit temperature from $12{ }^{\circ} \mathrm{C}$ to the target range. Mortality points above the horizontal dotted line were $100 \%$.

TABLE 2: Lethal time in days for $99 \%\left(\mathrm{LT}_{99}\right)$ mortality for one-day old codling moth eggs (95\% fiducial limits). Exposure times include times taken to reduce the fruit temperature from $12^{\circ} \mathrm{C}$ to the target range. Combined results, coolstorage only $\operatorname{cog} \log (p)=-1.5495[0.068]+$ $0.1330[0.005] t$; fumigation followed by coolstorage cloglog $(p)=$ $0.3066[0.943]+0.2043[0.204] t$ where $t=$ time in coolstore and $p=$ mortality.

\begin{tabular}{ccc}
\hline $\begin{array}{c}\text { Coolstorage target } \\
\text { temperature range } \\
\left({ }^{\circ} \mathrm{C}\right)\end{array}$ & Coolstorage only & $\begin{array}{c}\mathrm{LT}_{99} \\
\text { Methyl bromide fumigation } \\
\text { followed by coolstorage }\end{array}$ \\
\hline $0.5-1.0$ & 23.6 & 6.0 \\
$1.0-1.5$ & $22.1-25.6)$ & $(-)$ \\
& 24.4 & 7.2 \\
$1.5-2.0$ & $22.5-26.9)$ & 6.0 \\
& 23.2 & $(5.8-6.3)$ \\
Combined & $23.8-26.8)$ & 6.4 \\
& $(21-26.8)$ & $(5.7-7.2)$ \\
\hline
\end{tabular}

(-) could not be estimated or very wide limits 


\section{CONCLUSIONS}

The time taken to kill codling moth eggs was not increased as the mean fruit pulp temperature was increased from temperatures near 0.5 to temperatures near $2.0^{\circ} \mathrm{C}$, with or without fumigation. The treatment currently used for exporting apples to Japan is very robust, as complete mortality of fumigated codling moth eggs was observed after $18 \mathrm{~d}$ of storage, while the approved treatment specifications uses a mandatory $25 \mathrm{~d}$ period at temperatures of $0.5^{\circ} \mathrm{C}$ and below. Further research is required to determine if constant temperatures above $2.0^{\circ} \mathrm{C}$ result in an increase in survival of codling moth.

\section{ACKNOWLEDGEMENTS}

We thank ENZA (New Zealand) International for funding this research; John Maindonald and Patrick Connolly for statistical analyses; Sue Peetz for technical assistance and Dave Rogers and Michael Lay-Yee for manuscript revision.

\section{REFERENCES}

Dentener, P.R., Waddell, B.C., Batchelor, T.A., Birtles, D.B., O’Donnell, R.L., Stevens, P.S. and Wearing, C.H., 1988. Disinfestation of New Zealand apples. 1988. Report 1. 'Granny Smith' basic test. DSIR Technical Report . 54 pp.

Kawakami, F., Motoshima, S., Miyamoto, K., Soma, Y., Mizobuchi, M., Nakamura, M., Misumi, T., Sunagawa, K., Moku, M., Akagawa, T., Kato, T., Akiyama, H., Imamura, T., Tao, M., Kaneda, M., Sugimoto, S., Yoneda, M., Kadio, H., Katsumata, H., Nagai, H., Sasaki, M., Ichinohe, F., Kawashima, K., Kudo, T., Osanai, Y., and Saito, A., 1994. Plant quarantine treatment of 'Fuji' apples for export to the United States. Res. Bull. Pl. Prot. Japan. Supplement to No. 30: 180.

Lay-Yee, M., 1993. Response of New Zealand apples to methyl bromide fumigation. The Orchardist of N. Z. 66(10): 35-36.

Maindonald, J.H., Waddell, B.C. and Birtles, D.B., 1992. Response to methyl bromide fumigation of codling moth (Lepidoptera: Tortricidae) eggs on cherries. J. Econ. Entomol. 85(4): 1222-1230.

Moffitt, H.R. and Albano, D.J., 1972. Effects of commercial fruit storage on stages of the codling moth. J. Econ. Entomol. 65(3): 770-773.

Preisler, H.K. and Robertson, J.L., 1989. Analysis of time-mortality data. J. Econ. Entomol. 82:1534-1542.

Singh, P., Clare, G.K. and Ashby, M.D., 1985. Cydia pomonella. Pp 237-248 In: Handbook of Insect Rearing, vol 2, P. Singh and R.F. Moore (Eds); Elsevier, Amsterdam.

Toba, H.H. and Moffitt, H.R., 1991. Controlled-atmosphere cold storage as a quarantine treatment for non-diapausing codling moth (Lepidoptera: Tortricidae) larvae in apples. J. Econ. Entomol. 84(4): 1316-1319.

Waddell, B.C., 1992. Japanese market access for New Zealand apples: Development of a postharvest disinfestation treatment for codling moth. The Orchardist of New Zealand. 66(6):25, 47.

Waddell, B.C., Birtles, D.B. and Dentener, P.R., 1989. Methyl bromide fumigation for the control of codling moth (Lepidoptera: Tortricidae) on different cherry and nectarines cultivars: a cultivar comparison test. Proc. Australasian Conf. Postharvest Hort., B.B. Beattie (Ed). Pp 157-165.

Waddell, B.C., Dentener, P.R. and Petry, R.J., 1992. Disinfestation of New Zealand Apples. Confirmation Test. HortResearch Client Report No. 92/136. 92 pp.

Warner, G. 1995. Washington apples create excitement in Japan. Good Fruit Grower 46(4): 28-35. 